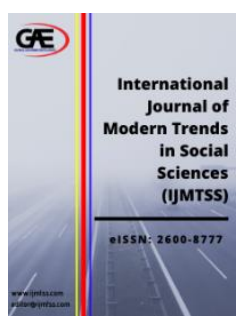

\author{
INTERNATIONAL JOURNAL OF \\ MODERN TRENDS IN \\ SOCIAL SCIENCES \\ (IJMTSS) \\ WWW.ijmtss.com
}

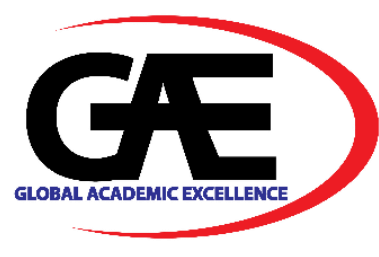

\title{
THE FOURTH HISTORICAL MOMENT IN SOCIAL RESEARCH 'THE CRISIS OF REPRESENTATION': A CHAPTER REVIEW
}

\author{
Asma Shughail Aqib Al Hashimi ${ }^{1 *}$, Adi Anuar Azmin ${ }^{2}$ \\ 1 Faculty of Applied and Human Sciences, Universiti Malaysia Perlis, Malaysia \\ Email: asmashughail@studentmail.unimap.edu.my \\ 2 Faculty of Applied and Human Sciences, Universiti Malaysia Perlis, Malaysia \\ Email: adianuar@unimap.edu.my \\ * Corresponding Author
}

\section{Article Info:}

Article history:

Received date:23.06.2021

Revised date: 04.07.2021

Accepted date: 25.09 .2021

Published date: 30.09 .2021

To cite this document:

Al Hashimi, A. S. A., \& Azmin, A. A. (2021). The Fourth Historical Moment In Social Research 'The Crisis Of Representation': A Chapter Review. International Journal of Modern Trends in Social Sciences, 4 (17), 138144.

DOI: $10.35631 /$ IJMTSS.417012

This work is licensed under $\mathrm{CC}$ BY 4.0 (c) (2)
Abstract:

The historical moments of qualitative research reflect socially constructed quasi-historic conventions that remain crosscut and overlapping till the present. This progressive narrative is well represented and assessed in a historical overview by Denzin \& Lincoln (2018) in their book "The Sage handbook of qualitative research" in the introduction "The discipline and practice of qualitative research". Through a chapter review, this article particularly discusses the fourth moment of Quantitative research coined as "The crisis of representation", which is believed to be the crossroads where social scientists remain entangled between the science and humanity perspective while conducting social research in order to forward social realities. This period of confusion simultaneously forwarded the multi-paradigm (positivism, postpositivism, and interpretivism), all of which have unique characteristics that are suitable for specific research. Thus, this paper sheds light on the overview of the crisis of representation and further explains the types of crises that occurred during this historical moment, including the crisis of representation, the crisis of legitimation, and a crisis of praxis. It is expected that apart from extending current literature this paper would support social scientists for selecting appropriate methods and paradigms as well as to justify their selection.

Keywords:

Social Research, Qualitative Methods, Crisis Of Representation, Chapter Review 


\section{Introduction}

Throughout time, scholars have adopted diverse approaches to research and present findings. Qualitative research as one such major approach represents a transitioning and overlapping historical system aimed at defining the social and historical background of the society. The reported eight major crosscuts of qualitative investigations include the tradition \{1900-1950\}, the modernist of the golden age $\{1950-1970\}$, the blurred genres $\{1970-1986\}$, the crisis of representation $\{1986-1990\}$, the post-modern $\{1990-1995\}$, the post-experimental inquiry $\{1995-2000\}$, the methodologically contested present $\{2000-2004\}$ in addition to the fractured future period that connects from 2005 to the present and beyond (Denzin \& Lincoln, 2018; Spooner, 2017). These major crosscuts of qualitative research are termed as historical moments. The moments are quasi-historic, socially constructed overlapping conventions that enable 'performance' of developing idea while facilitating an escalating sensitivity to and sophistication about the promises and pitfalls of ethnography and qualitative approach (Lincoln, 2017).

Based on research, qualitative method further operates in five major proposed figured spaces, namely positivist, modernism, critical, post-structural, and post-materialism, all developed on the concepts of research questions, knowledge, language, reality, and the relationship between objects and subjects (Jürgen, 2015). The crisis of representation, the fourth historical period, assumed as the up-to-date period, grabbed our attention for further research to answer the question of how this historical moment has impacted the social lives of the population (Wimmer \& Glick Schiller, 2019). This moment is exclusively represented and assessed in a historical overview by Denzin and Lincoln (2018) in their book The Sage handbook of qualitative research in the introduction The discipline and practice of qualitative research. The focus on this particular moment from the historical timeline of qualitative investigation is motivated by the consensus of majority scholars who indicated that the crisis of representation represents a crossroad where social scientists are entangled between the science and humanity perspective while conducting social research to forward social realities. Therefore, the main objective of this paper is to discuss the existing relationship between historical moments, research methods, politics, paradigms, communities of interpretive scholars, and research methods in qualitative research, majorly focusing on the fourth historical moment in social research, that is, the crisis of representation. Since, such an exploration was found missing in existing studies, it is expected that this paper would extend current literature and guide social scientists for selecting appropriate method and paradigm for future qualitative studies.

\section{Literature Review}

To adequately understand the concept of the crisis of representation, it is essential to first recognize the impact of the previous historical moments, particularly the third historical moment. The methodological moment emerged as a result of increased controversy and discussions between researchers following the early 1980s paradigm wars (Obiagu, Mezieobi, Aroh, \& Akubue, 2020). In fact, the blurred genres was the major reason behind the crisis of representation's existence. The blurred genres phase is a very important moment; wherein social researchers start thinking about social science research differently than the science researchers. Fox example, in science, everything can be quantified as the researchers in e.g., chemistry, physics, math, etc. follow positivist or post-positivist paradigm that outlines everything must be quantified and controlled in labs in an objective manner. However, in social science, it comes to social realities to understand a social phenomenon, e.g., globalization, or socialism. Hence, social science researchers cannot use the science tenets to measure globalization or socialism or examine the cause and effect. In social realities, such approach 
will not make sense. Social research is interpretive and tend to be subjective in order to reflect social reality. Accordingly, the blurred genres phase marks the starting of a historical moment that social researchers (e.g. literature, feminist, humanities, and others) used as a way to recognize how social realities is experienced and interpreted. This shift produced the next stage; the crisis of representation.

To further illustrate the crucial contributions of the third historical moment, Denzin and Lincoln (2018) outlined the two main versions of the moment. Version one for years has been highly rejected by the options of incommensurability and incompatibility (Klevan, Karlsson, Ness, Grant, \& Ruud, 2018).The primary form of criticism emerged right after the introduction of version one. In this regards, (Mohajan, 2018) points out that when implemented for the mixed methods of movement, researchers adapting qualitative methodologies brings forth the question of whether the research been disconnected from the main content, justice issues, and the prevailed methods of analysis that matter while defining the crisis of presentation?

The second version, on the other hand is categorized into three groups depending on the concepts presented by the specific scholar. The first group of version portrays two scholars aiming to explain the moral and political impacts brought about by the SBR movement (VanGyzen, 2014). The second group takes a different path as the scholars assume that each social community has its own way of life thus justifying different criteria of data interpretation (Mohajan, 2018). The third group of scholars are ones who makes all decisions based on researcher-subject relationship and research design while regulating the population and presenting informed consent, an approach that have been majorly assumed to limit academic freedom.

\section{Crisis of Representation}

The crisis of representation initiated with certain books, such as Writing culture- The poetics and politics of ethnography: A school of American research advanced seminar, written by Clifford and Marcus (1986), Anthropology as culture critique: An experimental moment in the human sciences, written by Marcus and Fischer (2014), and The Anthropology of experience, written by Turner and Bruner (2001). These three are just a few of many examples when scholars start to write about ethnographic, different culture. These works made research and writing more reflexive and called into question the issues of gender, class, and race. As the paradigm is shifted to interpretivism, social scientists no more study realities as the way it is done in science; however, they interpret realities following social science principles. Social scientists are produced and influenced socially, politically, and culturally, thus; the way they interpret the social realities originates from this impact. This explains the way social scientist make sense of reality that is the way they experience it. Thus, once the crisis of representation occurred, there was a recognition that social researchers are a part of the research process. They paved the way for subjectivity. From the ontology and epistemology perspective, the idea that knowledge is not produced in a lab, rather, knowledge is socially constructed emerged. It cannot be denied that social scientists play an important role in the way knowledge is produced as the paradigm shifted from positivist and post positivism epistemology to interpretivist epistemology. In this essence, social researcher mirrors the society's opinion. Hence, we argue, since subjectivity is important, reflexivity is also important. The time came for the role of narration to take its place in social research wherein the importance of social science narration is derived from the reflexivity of multi-realities that are produced through different paradigms. 


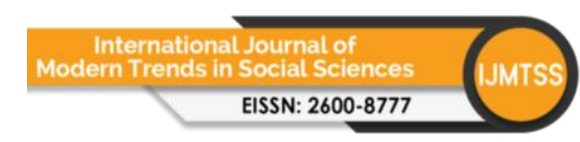

Volume 4 Issue 17 (September 2021) PP.138-144

DOI 10.35631/IJMTSS.417012

Crisis of representation can further be diagnosed with three major domains. The first group captured by art, media and literature, the second group deal with philosophy while the semiotics represent the third domain (Stanley \& Wise, 2013). As the society drives towards understanding its social reality, the domains of media and art, the fourth historical moment, that is, the crisis of representation continue to lose the modern painting referent while literature distance its arguments from the referential world reality governed by mass media and other digital platforms (Jarvie, 2016). The social scientists are thus required to look for innovative methods of inquiry to compensate the lack of representation in the modern world (Levack, Kayes, \& Fadyl, 2010). This brings forward the central question that is, where is the difference between the post modernism historiographic and the crisis of representation? The difference should have the potential to open to the society on the limits and possibilities the society will require to reach its absolute historical truth and reality. Thus, the question as for this case is, should the people change their way or lives, or should they continue to live in a less naïve and more careful manner? There is no longer a divine-eye view in the social sciences today that insures unmitigated qualitative certitude (Hayem, 2016). It is an era of uncertainty and multiparadigm life, that is, positivism post-positivism and perception. Social scientists therefore need to determine which method and paradigm to use and how to explain their process and justify their selection (Castleberry \& Nolen, 2018). Notwithstanding the above, all parties agree that each method has its unique set of conditions that must be followed. Universally, all investigation reflects the inquirer's viewpoint (Brown \& Lan, 2015) while all observation is laden to theory. Solely theoretical- or value-free knowledge does not exist. The days of naive realism and naive positivism are over (Levitt et al., 2018) and replaced by Critical and historical realism along with diverse versions of relativism (Gould, 2017). The research evaluation criteria are relative now and that is no longer fundamental.

Crisis of representation ironically can be underestimated as a single crisis; whereas, it is in fact is a combination of three crises; the plight of legitimation, praxis, and the crisis of representation (Verma, 2019). The three forms of crises in the moment of perspective of postmodernism and post-structuralism are further coded in different methods mainly based on the interpretive, feminist, race, postcolonial as well as a clear turn towards human disciplines (Anwaruddin, 2016). As revealed by experts, the fourth historical moment or the crisis of representation makes it clear whether it is impossible for an individual to understand the function ability or usability of an object through representation only without the direct lived experience (Thornber, 2015). In social science, however, understanding a social phenomenon relates to social realities. Researchers in social sciences cannot use the principles of science and measure globalization or socialism, nor examine the cause and effect (Claro, Paunesku, \& Dweck, 2016). Social research is interpretative and tends to be subjective as a reflection of social reality (Brown \& Lan, 2015). Thus, once the representation crisis occurred, it was recognized that social researchers are integral part of the research process (Austad, Hetlevik, Mjølstad, \& Helvik, 2016). Subjectivity paved the way. From the perspective of ontology and epistemology, the idea that knowledge is not generated in a laboratory emerged. Experience cannot be lifted by representation only, instead, it is developed in the social text (Bhargava, 2016). In particular, the crisis of legitimization points out how social scientists should command authority in a social version by critically rethinking and reevaluating essential aspects such as generalizability, validity, and reliability. In this context, Norman Kent Denzin, an American sociological professor is regarded as, "the Father of Qualitative Research." He was awarded due to the tireless efforts to ensure qualitative research is understood all over the world through conference organizations, editorship, scholarship, and his scholarly influence on the field (Castleberry \& Nolen, 2018). In collaboration with Lincoln, Norman was able to 


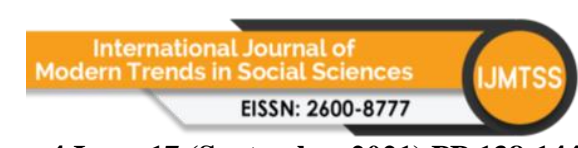

Volume 4 Issue 17 (September 2021) PP.138-144

DOI 10.35631/IJMTSS.417012

produce the magnificent project "Introduction: The Discipline and Practice of Qualitative Research. In N. K. Denzin, \& Y. S. Lincoln, The SAGE Handbook of Qualitative Research (pp. 1-23). UK: SAGE”, which formed the core subject matter of this paper.

Significantly, Interpretive researchers listen to diverse stakeholder viewpoints. They will advocate for the underdog side in any given situation (Flaherty, 2002). For example, they will demonstrate how the media reproduces stereotypes of gender, ethnicity, sexual orientation, and social status and even contribute to consumer behaviors that are detrimental to personal health and the environment (Denzin, 2015). In doing so, they participate in social critique and moral discourse, defining cultural capital's various gender roles that function in unique cultural contexts (Alase, 2017). An anti-fundamental, essential social science finds its outer basis not in science, in any of its revisionist, post-positivist forms, but dedication to post-Marxism and collective feminism with hope but no guarantees (Ahmed, 2020). Hence, production of social science knowledge must be understood by everyone from all social, cultural, and political backgrounds. Consequently, the practical crisis comes from answering all of the above questions wherein social sciences diverts from science to humanities as we arrive to the fourth moment of the representation crisis (Austad et al., 2016) that in in turn change in the concept of portraying work in a certain way and structure. This is how the research problem came in picture, and consequently, the representation crisis starts to exist (Brown \& Lan, 2015). The logic is simple, if we are trying to understand the complexity of social phenomena in social science; we need to shift to the lenses to humanities instead of science. Moreover, as societal changes to inter-relativism, social scientists are no longer studying realities as they do in science; instead, they are interpreting realities as they do in social science (Brown \& Lan, 2015). Social scientists are developed and impacted socially, politically, and culturally and because of this the way they interpret social realities is naturally different (Austad et al., 2016). This explains how fact is made sense by social scientists in the way they experience reality. Thus, once the representation crisis took place, there was an acknowledgment that social researchers are part of the research process (Brown \& Lan, 2015). To explain the contemporary life, the authors attempt to explain how power and ideology work in and through debate, cultural resources, and cultural texts structures, making the situation command deep concern in the modern world.

\section{Summary}

This paper was motivated by the understanding that a critical theory of the society, which combines historical, sociological, cultural, and political analysis, is urgently needed. Hence, through a chapter review of the introduction "The discipline and practice of qualitative research" from the book "The Sage handbook of qualitative research", this paper attempts to examine the fourth moment of Quantitative research coined as "The crisis of representation", which is believed to be most crucial among the historical moments of qualitative research. The work by Denzin and Lincoln (2018) represents a well-represented progressive narrative of the subject matter. Overlapping social science researchers are still following different type of paradigms that are interrelated across the eight historical moments of qualitative research. However, our focus on the crisis of representation moment is motivated from the confusion of whether the social science researcher should select the science or the humanity perspective. Our findings highlight that each of the perspectives has its own tenets, such as the type of paradigm (positivism or interpretivism), the use of first person or third person pronoun, the style of representation (narration or theory-based writing up), the social reality legitimation (through trustworthiness, flexibility, and ethics or through validity or reliability), and type of 
praxis (whether it is an academic endeavor or practical implication) that social scientists must commit to.

In terms of contributions, we believe that this paper can advance a more radical research agenda. In line with the theory and this paper found "The crisis of representation" articulating a society where people freely determine their desires and needs. Based on our review it is recommended that we need to develop new ways of evaluating critical qualitative work as participants belong from governmentality and social controlled systems. The issue is straightforward: critical inquiry must concentrate on a specific set of moral and political values linked to an established set of interpretive practices. We restate that "The crisis of representation" represent a crossroad that helps social scientists to understand what, how, and why they have to select an appropriate research method to put forth the social reality. Accordingly, it is expected that this paper would help researchers understand the overlap occurring among the previous three historical moments along with a nuanced understanding of how the following historical moments are working as well as the interplay that exists among all the eight historical moments based on the principles advocated by the crisis of representation.

\section{References}

Ahmed, N. A. (2020). The crisis of representation: A comparative discourse analysis of Somali and Western voices in Somali development research. University of Ottawa.

Alase, A. (2017). The interpretative phenomenological analysis (IPA): A guide to a good qualitative research approach. International Journal of Education and Literacy Studies, 5(2), 9-19.

Anwaruddin, S. M. (2016). Language teachers' responses to educational research: addressing the 'crisis' of representation. International Journal of Research \& Method in Education, 39(3), 314-328.

Austad, B., Hetlevik, I., Mjølstad, B. P., \& Helvik, A. S. (2016). Applying clinical guidelines in general practice: a qualitative study of potential complications. BMC family practice, 17(1), 92.

Bhargava, R. (2016). Effect of concept attainment model on achievement in social sciences. International Journal of Science and Research, 5(5), 699-701.

Brown, C. P., \& Lan, Y. C. (2015). A qualitative metasynthesis comparing US teachers' conceptions of school readiness prior to and after the implementation of NCLB. Teaching and Teacher Education, 45, 1-13.

Castleberry, A., \& Nolen, A. (2018). Thematic analysis of qualitative research data: Is it as easy as it sounds? Currents in Pharmacy Teaching and Learning, 10(6), 807-815.

Claro, S., Paunesku, D., \& Dweck, C. S. (2016). Growth mindset tempers the effects of poverty on academic achievement. Proceedings of the National Academy of Sciences, 113(31), 8664-8668.

Clifford, J., \& Marcus, G. E. (1986). Writing culture: the poetics and politics of ethnography: a School of American Research advanced seminar: Univ of California Press.

Denzin, N. K. (2015). The poststructural crisis in the social sciences: Learning from James Joyce." Postmodern representations: Truth, power, and mimesis in the human sciences and public culture. 38-59.

Denzin, N. K., \& Lincoln, Y. S. (2018). Introduction: The Discipline and Practice of Qualitative Research. In Y. S. L. In N. K. Denzin (Ed.), The SAGE Handbook of Qualitative Research (pp. 1-23). UK SAGE 
Flaherty, M. G. (2002). The crisis in representation: Reflections and assessments: Review symposium: Crisis in representation. Journal of contemporary ethnography, 31(4), 508516.

Gould, N. (2017). Qualitative research and social work: The methodological repertoire in a practice-oriented descipline.

Hayem, J. (2016). Marikana: analysing miners' subjectivity and the crisis of representation. Journal of Asian and African studies, 51(2), 171-185.

Jarvie, I. (2016). 11 Popper's Philosophy and the Methodology of Social Science. The Cambridge Companion to Popper, 284.

Jürgen, R. (2015). Historical epistemology and interdisciplinarity Physics, philosophy, and the scientific community (pp. 241-251). Dordrecht: Springer.

Klevan, T., Karlsson, B., Ness, O., Grant, A., \& Ruud, T. (2018). Between a rock and a softer place-A discourse analysis of helping cultures in crisis resolution teams. Qualitative Social Work, 17(2), 252-267.

Levack, W. M., Kayes, N. M., \& Fadyl, J. K. (2010). Experience of recovery and outcome following traumatic brain injury: a metasynthesis of qualitative research. Disability and rehabilitation, 32(12), 986-999.

Levitt, H. M., Bamberg, M., Creswell, J. W., Frost, D. M., Josselson, R., \& Suárez-Orozco, C. (2018). Journal article reporting standards for qualitative primary, qualitative metaanalytic, and mixed methods research in psychology: The APA Publications and Communications Board task force report. American psychologist, 73(1), 26.

Marcus, G. E., \& Fischer, M. M. (2014). Anthropology as cultural critique: An experimental moment in the human sciences: University of Chicago press.

Mohajan, H. K. (2018). Qualitative research methodology in social sciences and related subjects. Journal of Economic Development, Environment and People, 7(1), 23-48.

Obiagu, A. N., Mezieobi, D. I., Aroh, P. N., \& Akubue, F. N. (2020). The Effect of cooperative concept mapping on misconceptions, knowledge achievement, and transfer of learning in peace education. The Social Studies, 111(1), 18-38.

Spooner, M. (2017). Qualitative Research and Global Audit Culture The SAGE handbook of qualitative research (5 ed.): Thousand Oaks.

Stanley, L., \& Wise, S. (2013). Method, methodology and epistemology in feminist research processes In feminist praxis (pp. 20-60): Routledge.

Thornber, K. L. (2015). The real modern: literary modernism and the crisis of representation in colonial Korea by Christopher P. Hanscom, and: When the future disappears: The modernist imagination in late colonial Korea by Janet Poole. Harvard Journal of Asiatic Studies, 75(1), 191-201.

Turner, V., \& Bruner, E. (2001). The Anthropology of Experience (1986). Urbana and Chicago. VanGyzen, J. (2014). La Victoire du péril rose: Contextualizing sociological narratives and wagnerian aesthetics in lili boulanger's faust et hélène. Brandeis University.

Verma, V. (2019). A Crisis of Representation: Interests, Identities and Politics. Journal of Social Inclusion Studies, 5(1), 1-18.

Wimmer, A., \& Glick Schiller, N. (2019). Methodological nationalism, the social sciences, and the study of migration: an essay in historical epistemology. International migration review, 37(3), 576-610. 